Dagmar Estermann Meyer

Universidade Federal do Rio Grande do Sul

Carin Klein

Prefeitura Municipal de Canoas/RS

Maria Cláudia Dal'Igna

Universidade do Vale do Rio dos Sinos

Luiz Fernando Alvarenga

Universidade Federal do Rio Grande do Sul

\title{
Vulnerabilidade, gênero e políticas sociais: a feminização da inclusão social
}

\begin{abstract}
Resumo: O artigo desdobra-se de uma pesquisa realizada com gestores/as e técnicos/as, vinculados/as a secretarias municipais, envolvidos/as com a implementação de políticas e programas de inclusão social, em um município da Grande Porto Alegre/RS. Nele discutimos, na perspectiva dos estudos de gênero e estudos culturais pós-estruturalistas, um movimento de generificação que nomeamos de "feminização da inclusão social", focalizando a situação do emprego e as condições de trabalho, a infraestrutura dos serviços e os modos como profissionais/ técnicas se veem na implementação das políticas. Argumentamos que promover inclusão social pressupõe desenvolver e desempenhar um conjunto de capacidades representadas como sendo 'da ordem do feminino', que são constitutivas da feminização que as políticas incorporam e fazem funcionar.
\end{abstract}

Palavras-chave: vulnerabilidade; gênero; políticas; inclusão social.

Copyright @ 2014 by Revista Estudos Feministas.

1 Pesquisa financiada com bolsa $P Q$ do $C N P q$, intitulada Vulnerabilidade, programas de inclusão social e práticas educativas: uma abordagem na perspectiva dos estudos de gênero e culturais

\section{O texto em contexto}

Neste texto, analisamos parte dos resultados de uma pesquisa 'guarda-chuva'l que propôs, na modalidade de intervenção/formação, a discussão de resultados de um conjunto de investigações ${ }^{2}$ com gestores/as e técnicos/as vinculados/as a três secretarias (Educação, Saúde e 
(MEYER, 2008a). A equipe de pesquisa foi integrada pelas autoras e pelo autor deste texto e por Sandra Andrade, Letícia Fernandes, José Damico, Catharina Silveira e Jeane Félix da Silva.

${ }^{2}$ Dissertações e teses que problematizaram políticas e programas direcionados para a inclusão social, desenvolvidas pelo grupo na Grande Porto Alegre/RS: Carin KLEIN, 2003 e 2010; Letícia FERNANDES, 2008; Sandra ANDRADE, 2008; Maria Cláudia DAL'IGNA, 2011; José Geraldo DAMICO, 2011; Luiz Fernando ALVARENGA, 2012. Além da pesquisa de Dagmar MEYER et al., 2008b, cujos resultados tanto 'alimentaram' a pesquisa em foco quanto foram por ela 'nutridos' e tensionados.

${ }^{3}$ Com uma área territorial de $131,097 \mathrm{~km}^{2}$, Canoas possui uma população estimada em 323.827 habitantes, constituindo-se como um dos maiores conglomerados urbanos do estado do Rio Grande do Sul. Sobre Canoas, poderiam ser citadas algumas características importantes, como: ser vizinha da capital, Porto Alegre; possuir o segundo maior Produto Interno Bruto (PIB) do estado; ter a segunda maior rede de ensino e o quarto maior colégio eleitoral gaúcho; ser sede de grandes empresas multinacionais. Informações disponíveis em: < http://www.canoas.rs.gov.br/ uploads/paginadinamica/15857/ Canoas_em_Dados2012.pdf $>$ e $<$ http://www.canoas.rs.gov.br/site/ home/pagina/id/7>.

${ }^{4}$ Programa Bolsa Família, Primeira Infância Melhor, Programa Saúde da Família, Mais Educação, Programa Primeiro Emprego, Programa de Atenção Integral à Família entre outros. Não nos detivemos na análise de especificidades de tais políticas/programas, mas naqueles desafios/entraves/soluções que compõem os cotidianos de trabalho que, desde o ponto de vista de gestores/as e técnicos/as participantes, envolvem sua implementação.

${ }^{5}$ No campo da saúde, a educação permanente tem sido utilizada como estratégia pedagógica
Desenvolvimento Social) do Município de Canoas (Grande Porto Alegre/RS ${ }^{3}$ ), responsáveis pela implementação de programas de inclusão social. ${ }^{4} \mathrm{~A}$ pesquisa tomou como referência os pressupostos da educação permanente em saúde ${ }^{5}$ e, nessa perspectiva, o seu desenvolvimento demandou a elaboração negociada de um projeto formativo e de um conjunto de procedimentos e técnicas operacionais que visavam a favorecer o intercâmbio pedagógico entre realidades sociais e políticas distintas e o diálogo entre saberes e interesses aos quais, de modo geral, se atribuem estatutos sociais e políticos diferenciados. ${ }^{6}$

O referencial teórico-metodológico em que a pesquisa se insere articulou estudos de gênero e estudos culturais pósestruturalistas ${ }^{7}$ aos quadros conceituais da vulnerabilidade e da educação permanente em saúde. O corpus de análise foi composto por um conjunto de textos com diferentes características: registros escritos acerca dos processos de negociação e planejamento do curso, diários de campo produzidos durante sua realização e, ainda, grupos focais ${ }^{8}$ realizados com gestores/as, técnicas/os de secretarias e serviços envolvidos, e com os/as componentes da equipe de investigação, após o término do curso. Tais textos foram analisados na perspectiva da análise cultural, para responder a um conjunto de questões e objetivos que incluíram, entre outros, a possibilidade de discutir políticas e programas direcionados para a inclusão social, desde a perspectiva de gênero, com um conjunto de instituições/grupos envolvidos com sua operacionalização.

Quando propusemos esta pesquisa, vínhamos apontando, em nossas investigações, ${ }^{9}$ para um processo de dupla responsabilização de mulheres-mães (sobretudo de mães pobres), posicionadas como 'alvo' de políticas e programas de inclusão social. No âmbito desse processo, e na condição de usuárias-alvo, elas têm sido mobilizadas, ao mesmo tempo, como causadoras de boa parte dos problemas enfrentados por seus núcleos familiares e como agentes responsáveis pela promoção da inclusão social que se almeja - processo que nomeamos de politização contemporânea do feminino e da maternidade. ${ }^{10}$ Entretanto, tais investigações já vinham evidenciando, também, do ponto de vista das condições (materiais e simbólicas) de implementação das políticas que, sob muitos aspectos, de outras formas e com outros efeitos, essa responsabilização, bem como a vulnerabilidade da população usuária, se estende aos serviços e profissionais que com ela interagem.

Com os resultados evidenciados por esta pesquisa, em particular, passamos a analisar de modo mais acurado alguns desses desdobramentos e efeitos sobre os sujeitos e serviços responsáveis pela implementação das políticas, 
para potencializar a mudança nas práticas isoladas e verticalizadas, e se configura como política pública, no Brasil, desde 2004. Ricardo Ceccim (2005) argumenta que o propósito da educação permanente é formar profissionais comprometidos com um certo objeto e com sua transformação, o que demandaria dois deslocamentos importantes nas próticas pedagógicas usualmente implementadas sob as denominações de 'capacitação' ou de 'educação em serviço': o da ênfase na transmissão e no desenvolvimento, para atualização, de determinados conhecimentos e habilidades técnicas, que pretendem reafirmar e reforçar a expertise e o domínio dos/as profissionais sobre um campo de saber/fazer, e o da elaboração e disseminação de prescrições e generalizações que permitiriam 'dar conta' de problemas/ objetos cujos contornos deixam de considerar as especificidades dos contextos que os constituem.

${ }^{6}$ Dessa negociação, resultou um programa de encontros semanais ao longo do segundo semestre de 2009 , de 48 horas/aula, que contemplou três eixos temáticos:

1) os conceitos de risco, vulnerabilidade e inclusão social e suas implicações práticas; 2) o conceito de família e seu posicionamento como alvo e como agente de inclusão social (de crianças, jovens, mulheres e idosos): possibilidades e limites; 3) saúde, escolarização e acesso a serviços sociais básicos como estratégias de inclusão social: possibilidades e limites. Participaram 22 técnicos/as e gestores/as atuantes nas secretarias envolvidas, seis estudantes de pós-graduação ou recém-doutores, a orientadora $e$ uma bolsista de iniciação cientííca. A participação foi oficializada com a assinatura de um termo de consentimento livre e esclarecido.

7 Desse referencial, destacamos a centralidade da linguagem (em sentido amplo) nos processos de produção das relações que a cultura estabelece entre corpo, sujeito, conhecimento e poder (Stuart HALL, 1997); o entendimen- localizando-os no contexto de um movimento que nomeamos como "feminização da inclusão social". Este artigo procura apresentar e descrever contornos desse movimento no (e a partir do) percurso analítico que realizamos.

\section{A generificação da inclusão social: (re)construindo uma problemática}

Um conjunto de autoras feministas ${ }^{11}$ tem reiterado que mulheres de diferentes estratos sociais estão sendo posicionadas como importantes agentes de implementação de ajustes econômico-sociais que redundam em cortes e/ ou diminuição de serviços sociais - a chamada "ressignificação das funções do Estado", produzida pelas políticas neoliberais,$-{ }^{12}$ e isso tem intensificado tanto o trabalho que elas realizam no plano familiar quanto fragilizado o seu trabalho no plano profissional. Como decorrência, as mulheres têm sido interpeladas, também de diferentes modos e cada vez mais incisivamente, como 'produtoras' de educação e de saúde no âmbito de suas famílias, em suas comunidades e em seu contexto profissional, uma vez que as profissões/ocupações envolvidas com proteção, promoção e provisão de cuidado são desenvolvidas predominantemente por mulheres. ${ }^{13}$

Nessa direção, é possível analisar a feminização da inclusão social à qual nos referimos a partir do que apreendemos, nas discussões realizadas com as/os profissionais no campo de investigação, como dificuldades, entraves, capacidade de resistir, de fazer muito com pouco, de doarse e resignar-se e que, ainda com muita frequência, é apresentado como 'competências' e capacidades que integrariam uma suposta 'natureza feminina'; competências que, reconhecida e efetivamente, contribuem para transformar cotidianos de vidas muito complexos, conflituosos, precários e contestados; e que, exatamente porque estão alocadas no domínio da 'natureza', passam a ser representadas como competências 'tácitas'.

Esse termo é utilizado, aqui, com o sentido que Daniele Kergoat ${ }^{14}$ atribuiu ao conceito de qualificações tácitas: componentes implícitos e não organizados da qualificação, adquiridos pela socialização lato sensu e que incluem habilidades, atitudes, comportamentos e valores, além de conhecimentos e técnicas que se tornam indispensáveis ao tipo de trabalho realizado, mas não são valorizados como qualificação estrito senso Em convergência com essa noção, mulheres ocupariam determinadas posições no mercado de trabalho e desenvolveriam determinadas funções e tipos de trabalho, não porque foram bem formadas para elas pelo sistema educacional, "mas porque são bem formadas pelo 
to de que a cultura é um campo de luta e contestação em que se produzem os sentidos e os sujeitos que constituem os diferentes grupos sociais em sua singularidade (Tomas Tadeu SILVA, 1999; Judy GILES and Tim MIDDLETON, 1999); o entendimento de que é por meio da educação (também tomada em sentido amplo) que indivíduos são transformados e se transformam em sujeitos de uma cultura. E que esse "tornar-se sujeito de uma cultura", nas sociedades contemporâneas, é fortemente mediado por políticas públicas, em especial aquelas que envolvem os campos da saúde e da educação (Cris SHORE e Susan WRIGHT, 1997; MEYER, 2011).

${ }^{8}$ Foram realizados quatro grupos focais: dois com técnicos/as e gestores/as, para investigar a implementação de programas de inclusão social; e dois com a equipe de pesquisa, em março de 2010, para discutir o alcance e as reverberações pedagógicas do trabalho de pesquisa realizado na modalidade intervenção/ formação.

${ }^{9}$ Além das já citadas, ver: MEYER, 2006; MEYER; KLEIN; FERNANDES, 2012.

${ }^{10}$ MEYER, 2006.

11 Claudia ANZORENA, 2010; Silvia DUSCHATZKY, 2008; Silvana MARIANO, 2009.

${ }^{12}$ Zygmunt Bauman (1999) analisa esse processo de ressignificação das funções do Estado na contemporaneidade, sinalizando que Estado moderno proporcionava subsistência e segurança à maioria da população. A ele cabia a função de garantir os meios de manter a população protegida. Entretanto, nas últimas décadas, alega-se que não é mais possíve custear esse Estado. No mundo atual, sua função foi alterada, e a tarefa de lidar com os riscos tem sido transferida para os próprios sujeitos. Trata-se, agora, de uma forma de governar que investe em ações de assistência e de um Estado assistencialista que, cada vez mais, investe nos sujeitos de modo a dirigi-los em favor do mercado (FOUCAULT, 2008). Isso conjunto do trabalho reprodutivo" 15 para o qual são educadas.

Do ponto de vista marxista da divisão sexual do trabaIho, tal noção tem sido útil para explicar questões como: salários desiguais para homens e mulheres que desempenham as mesmas funções; dificuldades de inserção de mulheres e homens em determinadas posições ou profissões; prevalência de mulheres em determinadas profissões (voltadas ao cuidado, por exemplo). Estudos que discutem o trabalho também utilizam noções como flexibilização e precarização para analisar situações de emprego, processos de organização e condições de trabalho. ${ }^{16}$ Nesta investigação, esses estudos e essas noções ajudam a entender como se reconfigura e se atualiza, no contexto da racionalidade neoliberal, no Brasil contemporâneo, o processo que nomeamos de feminização da inclusão social.

Aqui, políticas são compreendidas como artefatos centrais de organização social, porque promovem seus objetivos por meio da normatização e administração de várias esferas da vida cotidiana dos sujeitos aos quais se direcionam, educando-os para pensar, sentir e agir de certos modos, e não de outros. ${ }^{17}$ Concebê-las dessa maneira autoriza dizer que um dos modos de conhecer suas formas de funcionamento e seus efeitos passa pelo exame de relações de poder colocadas em ação nas proposições programáticas dos governos que as promovem, os quais, através de suas instituições e nas práticas assistenciais e educativas a elas vinculadas, investem sobre as famílias no sentido de instituir 'modos de viver a vida' que devem produzir o que, nelas, se entende como inclusão social (saúde, educação, acesso a bens e serviços e ao trabalho). Autoriza discutir, ainda, como tais políticas incidem sobre os sujeitos gestores e técnicos e sobre seus contextos profissionais, porque instituem modos de organização do trabalho em instituições e serviços públicos, bem como modos de viver e de fazer desses sujeitos que, assim, também produzem e governam. Permite, por fim, dizer que as políticas incidem sobre as redes de significação de gênero dos contextos em que emergem, ao mesmo tempo que são atravessadas e afetadas por elas; ou seja: as políticas são generificadas, e, nesse caso, argumentaremos que essa generificação resulta, atualizada e ressignificada, em feminização.

Utilizamos o conceito de gênero afastando-nos de abordagens que focalizam subordinações e desigualdades como sendo derivadas do desempenho de papéis, funções e características culturais estritas de mulheres e de homens, para assumir que o social e a cultura, lato sensu, são constituídos, atravessados e organizados por discursos instituintes de feminilidades e de masculinidades que, ao mesmo tempo, os produzem e ressignificam. Isso implica considerar, 
não significa que o Estado esteja enfraquecido; ao contrário, significa que no cenário atual a presença do Estado neoliberal pode ser traduzida em cada prática, em cada sujeito. Por isso, dever-se-ia evitar expressões como 'Estado mínimo'.

${ }^{13}$ Denise GASTALDO et al., 2005; Lesley DOYAL, 2001.

${ }^{14}$ Danièle KERGOAT, 1989.

15 KERGOAT, 1989, p. 94.

${ }^{16}$ Marília Pinto de CARVALHO, 2000; e Silvana MARIANO e Cássia CARLOTO, 2009.

17 Cris SHORE; Susan WRIGHT, 1997.

18 MEYER, 2011

19 José Ricardo de Carvalho Mesquita AYRES et al., 2003, $p$. 123.

${ }^{20}$ François DELOR; Michel HUBERT, 2000 entre outras coisas, que as instituições sociais, os símbolos, as normas, os conhecimentos, as leis, as doutrinas e as políticas de uma sociedade são constituídas e atravessadas por pressupostos de gênero, ao mesmo tempo que estão implicadas com sua produção, manutenção e ressignificação. ${ }^{18}$ Demanda compreender, também, os diferentes modos pelos quais o gênero opera estruturando o social, e é esta dimensão do conceito que priorizamos para descrever dimensões da generificação, aqui traduzida como feminização.

Recorremos, ainda, à noção de vulnerabilidade, que supõe "considerar a chance de exposição das pessoas [a agravos e problemas sociais] como a resultante de um conjunto de aspectos não apenas individuais, mas também coletivos [e] contextuais" 19 que estão implicados com uma maior suscetibilidade a eles e, concomitantemente, com a maior ou menor disponibilidade de recursos de proteção. Seu uso demanda o exame de processos de "distribuição desigual do risco" e de diferenciação social que se materializam como desvantagens de diversos tipos, ${ }^{20}$ o que ajuda a compreender como determinados grupos e sujeitos se tornam, em determinado tempo e lugar, mais suscetíveis a determinados agravos do que a outros. É o componente programático da vulnerabilidade que nos interessa aqui. Ele inclui o grau e a qualidade de compromisso, recursos, gerência e monitoramento de prevenção e cuidado que são importantes para identificar necessidades, canalizar recursos sociais existentes e otimizar seu uso. Envolve as formas que tais políticas efetivamente assumem na concretude das práticas que são desenvolvidas nos diferentes níveis de sua implementação; envolve, ainda, os processos formais de produção de conhecimento, tanto em termos do que se prioriza conhecer, do incentivo político e financeiro que decorre da priorização do que se busca conhecer, quanto da decisão política que determina a maior ou a menor viabilidade, validade e visibilidade desses conhecimentos. Além disso, comporta também as políticas de formação profissional, os processos de gestão dos serviços, a organização de processos de trabalho, entre outras coisas que estão implicadas com sua operacionalização.

De dentro desse quadro conceitual, voltamo-nos, então, para a discussão da problemática antes anunciada, delimitando-a, neste artigo, em torno de um dos focos que pudemos apreender, delimitar e discutir com o material empírico que produzimos na pesquisa: o processo de generificação em conexão com a precarização do emprego e das condições de trabalho, com a infraestrutura dos serviços e, sobretudo, com os modos como as profissionais se veem nessa organização, no entorno dessas políticas. 


\section{Cenas da inclusão social: fragmentos da generificação que (re)produz feminização}

Passamos, agora, a problematizar algumas cenas que, em nosso entender, possibilitam descrever dimensões do processo de generificação da inclusão social antes anunciado. São cenas recortadas de investigações que analisaram políticas como o Programa de Atenção Integral à Família (PAIF), o Primeira Infância Melhor (PIM), o Programa Bolsa Família (PBF), o Programa Nacional de Segurança Pública e Cidadania (Pronasci), em dois municípios da Grande Porto Alegre que integraram os projetos que realizamos. Tais cenas se rearticulam, atualizando e recompondo novas e outras cenas, reiteradamente descritas pelas participantes nas discussões geradas nesta pesquisa.

Assim, por exemplo, nos programas mencionados (assim como no sistema de ensino público, nos Centros de Referências da Assistência Social e na própria Estratégia Saúde da Família, entre outros) se prevê a contratação temporária de técnicos/as (ou estagiários/as) para suprir a falta de profissionais existente nas redes. Os estágios têm duração de seis meses a um ano, podendo, em alguns casos, ser renovados uma ou duas vezes. A contratação se dá por meio da terceirização de serviços, com a criação de cooperativas e/ou fundações municipais, que efetuam contratações celetistas sem previsão de promoções e/ou planos de carreira e que executam políticas de baixos salários. Essas formas de contratação, as disputas políticas locais e a burocracia envolvida no repasse de verbas aos municípios resultam, então, em evasão e circulação de funcionários e, também, em descontinuidades nos processos assistenciais e de educação em saúde pelos quais esses/ as técnicos/as seriam responsáveis. Isso que estamos relatando pode ser analisado em duas dimensões.

${ }^{21}$ Helena HIRATA, 2011. No contexto macropolítico, Helena Hirata, ${ }^{21}$ ao refletir sobre o processo econômico em curso e o movimento de globalização observado desde o início dos anos 1990, nos ajuda a entender que nessa forma de organização social se desenvolve tanto um processo de precarização social, familiar e do trabalho (que para ela são indissociáveis) quanto a diminuição da proteção social, a redução e o sucateamento dos serviços públicos. Paradoxalmente, tal contexto está implicado também com a criação e a ampliação de políticas sociais focalizadas ou (como contemporaneamente são chamadas) políticas de inclusão social, voltadas para segmentos específicos da população: desempregados, famílias pobres, jovens desempregados e que moram em contextos de violência extrema, gestantes, mulheres chefes de família, crianças sem acesso a educação formal etc. Hirata 
22 HIRATA, 2011 , p. 18.

${ }^{23}$ O PIM tem como objetivo "orientar as famílias e gestantes, a partir de sua cultura e experiências, para que promovam o desenvolvimento integral de suas crianças" (RIO GRANDE DO SUL, 2007, p. 7). Entre os critérios de seleção das áreas beneficiadas pelo PIM, está o número de famílias cadastradas no Programa Bolsa Família (PBF), menor número de crianças assistidas em escolas infantis, maior taxa de mortalidade infanti e maior vulnerabilidade social.

${ }^{24} \mathrm{Ao} / \mathrm{à} \mathrm{visitador/a} \mathrm{cabe} \mathrm{atua}$ diretamente nas comunidades cujas famílias são cadastradas na política. Ele/a deve cadastrar, planejar, orientar, desenvolver atividades, elaborar materiais, acompanhar e controlar a qualidade das ações educativas que as famílias devem realizar, através da realização da estimulação 'adequada', visando ao desenvolvimento integral das crianças de zero a seis anos, desde a gestação (RIO GRANDE DO SUL, 2007, p. 12)

${ }^{25}$ As ações programáticas ocorriam através do desenvolvimento das 'modalidades de atenção', previstas na metodologia PIM modalidade individual (que ocorre nas residências, com famílias que possuem crianças de zero a três anos), modalidade grupal (ocorre nas escolas ou em centros comunitários com os/as cuidadores/as e as crianças de três a seis anos). visitas de acompanhamento (com as gestantes ou famílias cadastradas que não comparecem aos encontros), reuniões comunitárias com as gestantes e atividades comunitárias.

${ }^{26}$ De acordo com as entrevistas realizadas com as visitadoras e com uma das integrantes do Grupo Técnico Municipal, durante a pesquisa, os primeiros processos de seleção para a contratação de visitadoras levaram em conta critérios como: residir na comunidade possuir primeiro grau completo e ter alguma vinculação com trabalhos comunitários naquela localidade. adverte sobre as consequências da precarização do trabalho:

O trabalho precário conduz à intensificação do trabaIho, porque há uma ameaça sobre os trabalhadores estáveis dos que estão desempregados e que procuram trabalho, e que estão dispostos, de certa forma, a aceitar condições salariais e condições de trabalho mais difíceis e mais penosas. Ao mesmo tempo, essa intensificação é também o resultado das novas formas de organização do trabalho e da produção. Trata-se de organizações flexíveis do trabalho e da produção, essenciais para a própria reprodução do sistema de trabalho e de emprego no momento atual. ${ }^{22}$

Nessa direção, na pesquisa sobre um dos programas focalizados, que emerge em tal contexto - o PIM -,${ }^{23}$ uma das autoras, que também atua como técnica no município em foco, relata efeitos do vencimento dos contratos e da não recontratação (durante dois anos) das visitadoras domiciliares ${ }^{24}$ no desenvolvimento das ações programáticas. ${ }^{25}$ Ela narra que, ao término de um encontro de capacitação do qual participou, Ema (uma ex-visitadora muito experiente) perguntou aos técnicos sobre as novas contratações, dizendo que ela e seu marido estavam desempregados e precisavam trabalhar. A ex-visitadora contou ainda que, antes de ser contratada pela primeira vez, em 2003, havia ficado por um período de oito meses trabalhando como voluntária e que chegou até a vender coisas de dentro de casa para sobreviver. Assim como nesse encontro, era recorrente encontrar e contar com a participação de exvisitadoras nas atividades da política, pois elas participavam das festas, das capacitações e das atividades educativas na comunidade como 'voluntárias', ${ }^{26}$ mas com um propósito muito claro: serem vistas, recontratadas e voltarem a trabalhar no PIM.

Quando articulamos o contexto macropolítico descrito por Hirata a esse contexto local, podemos dizer que, quando ex-visitadoras buscam marcar sua presença nessas atividades, dispondo-se até a trabalhar sem receber um salário, demonstram tanto o desejo e a capacidade de cumprir uma espécie de missão social (redentora) quanto a fragilidade que cerca as relações de trabalho, o que se expressa na precariedade das formas de contratação, na representação que fazem da função, nas justificativas com as quais legitimam suas atividades e que, em conjunto, acabam por organizar e dirigir o seu exercício profissional. Na mesma direção, pode-se dizer também que, de modo geral, as mulheres da comunidade que busca(va)m ser contratadas como visitadoras se encontravam em situações de trabalho precário muito próximas às do público-alvo da 
${ }^{27}$ Em março de 2007, período em que se iniciou o trabalho de campo, havia sete visitadoras e uma monitora contratada. Esses contratos foram gradativamente sendo encerrados até junho daquele ano. Pela ausência das contratações, a previsibilidade da política se rompia, e a equipe de técnicos/ as precisava lançar mão de modalidades de atendimento que não estavam delineadas nas orientações e na metodologia. Pelo que acompanhamos no município, a não contratação estava diretamente associada a tensões político-partidárias (KLEIN, 2010). ${ }^{28}$ Este é um dos programas desenvolvidos sob tutela do Ministério do Desenvolvimento Social e Combate à Fome (MDS). Ele integra a rede de atendimento do Sistema Único de Assistência Social (SUAS), na modalidade da Proteção Social Básica. O trabalho tem um caráter continuado e é desenvolvido nos Centros de Referências da Assistência Social (CRAS). Entre os principais objetivos do PAIF, destacam-se "o fortalecimento da função protetiva da família; a prevenção da ruptura dos vínculos familiares e comunitários; a promoção de ganhos sociais e materiais às famílias; a promoção do acesso a benefícios, programas de transferência de renda e serviços socioassistenciais; e o apoio a famílias que possuem, dentre seus membros, indivíduos que necessitam de cuidados, por meio da promoção de espaços coletivos de escuta e troca de vivências familiares". Informações disponíveis em: < http://www.mds.gov.br/ assistenciasocial/protecaobasica/ servicos/protecao-e-atendimentointegral-a-familia-paif $>$.

${ }^{29}$ MEYER et al., 2008b. política e que, uma vez empregadas em contratos temporários, estes não lhes garantiam estabilidade de emprego.

No contexto local, a suspensão da recontratação das visitadoras - posicionadas no texto programático do PIM como sujeitos centrais das atividades educativas a serem realizadas com as famílias das crianças assistidas - implicou também a supressão de um acompanhamento mais direto às residências e da realização das atividades educativoassistenciais que se desenvolviam nesse ambiente; parte delas foi incorporada ao trabalho de modalidade grupal realizado, uma vez por semana, com outras conformações e condições. ${ }^{27}$ Assim, os encontros semanais, que deveriam ocorrer nos domicílios a fim de incentivar o cuidado e o desenvolvimento infantil, passaram a ocorrer sob a condução de técnicos/as e não mais de visitadoras, em uma associação comunitária. Nesse local, a precariedade de recursos e estrutura física tornava-se um aspecto limitador importante: cadeiras quebradas, sujeira, repartições inadequadas, falta de iluminação, falta de material e compartilhamento do espaço com outras ações (alfabetização de mulheres, informática, doação de ranchos e donativos). Além disso, as mulheres precisavam levar as crianças para os encontros, de forma que a realização das atividades educativas acabava se desenrolando em meio a choros, brincadeiras, animais, barulhos e dispersão. Para chegar a seus locais de trabalho, a equipe de técnicos/as utilizava meios de transporte próprios, trazia e/ou improvisava material pedagógico e de apoio, evidenciando grandes fragilidades e desafios para a execução da política e da própria 'rede de proteção' pública mais ampla.

Se considerarmos ainda que a criação e o fortalecimento de vínculos entre a população assistida e os serviços públicos são destacados como importantes para efetivar a adesão das famílias a programas de inclusão social como esses, pode-se argumentar que a grande rotatividade de profissionais, a precariedade das relações de trabalho e sua intensificação, muitas vezes intercalada com a falta de profissionais nos serviços - decorrente desses contratos temporários ou subcontratos -, é um condicionante importante da (não) efetividade do trabalho realizado. Como sinaliza uma técnica do Programa de Atenção Integral à Família (PAIF), ${ }^{28}$ de outro município da Grande Porto Alegre, em uma pesquisa já concluída: ${ }^{29}$

Essa rotatividade dos profissionais faz com que tenha uma descontinuidade no trabalho, porque tu não sabes até que ponto a pessoa trabalhou isso, até que ponto foi trabalhado. E aí a migração das famílias de programas pra programas. Então a família tinha uma situação de trabalho infantil e estava no Programa de 
30 CARVALHO; VIANA, 1994; Lena LAVINAS; Bila SORJ, 2000.

31 CARVALHO, 1996; Álvaro Moreira HYPOLITO, 1994; Eliane Marta Teixeira LOPES, 1991; e Guacira Lopes LOURO, 1997.

${ }^{32}$ Carin KLEIN; Dagmar MEYER Zulmira BORGES, 2013.

${ }^{33} \mathrm{Em} \mathrm{2003}$, uma das autoras realizou uma pesquisa documental na qual analisou o Programa Nacional Bolsa-Escola (KLEIN 2003), que atualmente faz parte do PBF. Na investigação, foi possível visibilizar como - a partir das argumentações em torno do processo de distribuição de renda e inclusão social - se buscou investir e (re)construir relações sociais generificadas, modificando e/ou reiterando lugares, espaços e funções para homens e mulheres. O que ali se enfatizava é que ações políticas de distribuição de renda, que visavam a dar conta da erradicação do trabalho infantil e de $100 \%$ das crianças na escola, poderiam ser facilmente alcançáveis, desde que houvesse empenho, dedicação e vontade das mulheres e mães brasileiras. Na cartilha 100 perguntas e respostas sobre a Bolsa-Escola, o então governador do Distrito Federal, Cristovam Buarque, diz: "A Bolsa Escola é um benefício pago à família, de preferência ò mãe [...] ou a outra figura feminina que tenha poder de decisão e controle sobre as crianças a serem beneficiadas" (Cristovam

BUARQUE, 2000, p. 14)

${ }^{34}$ Raquel RAICHELIS, 2010.
Erradicação do Trabalho Infantil (PETI) até as crianças completarem 15 anos, aí continua a situação de vulnerabilidade e as crianças saem do PETI pra ir pro Agente Jovem, por exemplo, e aí o profissional é outro, começa a trabalhar tudo de novo [...]; o município está tentando [...] reverter isso, fazendo a contratação de novos profissionais do quadro mesmo de funcionários, justamente porque a gente sinaliza muito isso, a necessidade do trabalho continuado, tanto pela vinculação com o profissional que está lá quanto pela continuidade do mesmo. (Entrevista - 10/1/2007)

Assim, a precarização que se expressa em contratos de trabalho temporários atinge, no contexto dessas políticas, tanto os indivíduos com menor escolarização e sem formação profissional formal quanto os profissionais formalmente qualificados. E, nesse caso, tal precarização abrange fundamentalmente funções e ações conectadas ao cuidar, especialmente ao cuidado com educação, proteção social e saúde, que têm sido historicamente representadas como femininas. Vários estudos $^{30}$ discutiram os efeitos disso tanto para as mulheres quanto para profissões como magistério, enfermagem, serviço social etc. Inscreve-se, nesse contexto, toda a gama de estudos que, no campo da sociologia da educação e dos estudos feministas, discutiram a proletarização e a feminização do magistério nos anos 80 e 90 do século passado. ${ }^{31}$ A problemática, portanto, parece reproduzir-se e atualizar-se, para tornar-se muito mais complexa nas sociedades neoliberais globalizadas. ${ }^{32}$

Nessa direção, de acordo com Luz Arango (2010), tal precarização estaria dentro do que pode ser denominado como 'economia do cuidado', sustentada e desenvolvida fundamentalmente por meio das mulheres (ou das funções tomadas como femininas) em função das 'competências tácitas', já apontadas anteriormente, e que se inscreve em uma lógica que nomeia e posiciona como centrais, nesse mercado do cuidado, tanto as/os profissionais que atuam nos serviços da saúde, educação e assistência social quanto as mulheres-mães - como provedoras, protetoras, cuidadoras e educadoras 'naturais' das crianças. Elas necessitam absorver as tarefas necessárias e de menor valor de remuneração e valorização, em contextos locais ou em comunidades específicas. ${ }^{33}$

$\mathrm{Na}$ mesma direção, Raquel Raichelis ${ }^{34}$ analisa perspectivas e dilemas que cercam profissionais da assistência social que vêm sendo reconhecidos como referência em políticas de assistência social, como o Sistema Único de Assistência Social (SUAS). Ela argumenta que, com elas, vem ocorrendo uma rápida expansão do mercado de trabalho para assistentes sociais por todo o território nacional, mas 
${ }^{35}$ RAICHELIS, 2010, p. 758.

${ }^{36}$ RAICHELIS, 2010, p. 758.

${ }^{37}$ Disponível em: <http://www.egem org.br/arquivosbd/basico/0.3681 87001253287033 4._unidade_iii_ cras_e_paif.pdf $>$. Acesso em: 13 mar. 2013. que, paradoxalmente, tal expansão vem sendo regida por "contratos terceirizados, subcontratados, temporários, [...] em tempo parcial ou por projeto, para citar apenas algumas formas de fragilização" 35 a que tais profissionais agora estão expostas.

Tal cenário se repete em outros programas e instituições implicadas com a inclusão social e, nele, vêm se intensificando "mudanças nos processos de organização, gestão e nas relações e vínculos laborais" que incidem na retração do trabalho regulamentado e resultam em "amplos contingentes de trabalhadores flexibilizados, informatizados, precarizados, desprotegidos de direitos e desprovidos de organização coletiva", ${ }^{36}$ também na esfera do Estado. Para ela, essa dinâmica acaba por obscurecer a responsabilidade do Estado na (falta de) efetividade das ações direcionadas para os usuários, uma vez que os sujeitos que as implementam estão subordinados à lógica dos mercados, a prazos contratuais exíguos e precários, e a recursos financeiros e estruturais insuficientes.

Tudo isso repercute na qualidade do trabalho técnico, na continuidade das ações e na manutenção de vínculos com os serviços, alimentando o descrédito da populaçãoalvo nas ações públicas. Entretanto, os mesmos processos que legitimam vínculos laborais precários na esfera do Estado também reposicionam o sujeito mulher: já responsabilizado pelo cuidado na esfera doméstica e familiar, passa a ser também responsabilizado, de outro modo e com outras funções, como profissional/agente responsável pela inclusão social na esfera de políticas públicas, como o PAIF, que sinalizam, dentre seus objetivos, "desenvolver ações e serviços básicos [...] tendo por perspectivas o fortalecimento de vínculos familiares e comunitários [...] e a ampliação da capacidade de proteção social e de prevenção de situações de risco no território de abrangência", ${ }^{37}$ como refere um documento normativo de um desses programas.

Com isso, reforçamos nosso argumento de que tanto a precarização dos serviços de saúde/educação/assistência social como a responsabilização das mulheres-mães estão imbricados na mesma lógica que potencializa e ao mesmo tempo torna precário o trabalho de técnicos e técnicas, bem como a atuação das mulheres das comunidades. Assim, esses dois efeitos são partes de um mesmo processo, que aciona mecanismos e estratégias diversos de responsabilização que produzem diferentes efeitos para e sobre esses diferentes sujeitos.

Assim, no contexto de uma discussão acerca dos limites que a falta de estrutura adequada de trabalho coloca ao desenvolvimento das ações programáticas, as profissionais se perguntam:

894 Estudos Feministas, Florianópolis, 22(3): 885-904, setembro-dezembro/2014 
${ }^{38}$ É importante não perder de vista que estamos nos referindo ao estado do Rio Grande do Sul e a municípios situados na Grande Porto Alegre, locais que fazem parte de regiões que apresentam os maiores índices de PIB e de IDH do país.

${ }^{39}$ Termo usado no RS para se referir a carteiras ou cadeiras escolares.
Técnica da SMS: Mas por que nós nos responsabilizamos? Porque a gente está trabalhando pela política pública, e que mecanismos nós, lá na ponta, podemos utilizar para mudar essa realidade que está inscrita, em um formato que não está servindo?

Técnica da SMDS: Daí eu fico pensando, pra que inaugurar o equipamento e dizer que nós vamos fazer a política, quando nós não temos condições de atender a todos [...] como é que nós noticiamos que vamos atender denúncias de violência, que nós vamos resolver e quando a gente vai lá verificar a denúncia, [...] a gente não consegue fazer a segunda intervenção mais imediata? Isso está acontecendo e me incomoda muito [...]. (Grupo Focal, 9/4/2010)

Ao mesmo tempo em que reconhecem e nomeiam limites, elas mesmas indicam que não só assumem como chamam para si tanto a responsabilidade de resolver os problemas da população usuária que demanda seus serviços quanto os problemas estruturais e institucionais básicos de competência do Estado - que travam a implementação e o alcance das ações de inclusão. Um exemplo contundente disso é o relato em que uma das participantes do curso, que é professora de ensino fundamental da rede municipal, descreve sua sala de aula, que funcionava provisoriamente dentro de um contêiner ${ }^{38}$ e quando chovia ficava alagada. Nesse ambiente, ela recebia seus/suas alunos/as, orientavaos/as a se sentarem nas 'classes' 39 com as pernas e os pés cruzados sob o corpo, e começava a rotina pedagógica do dia, enquanto ia tirando a água da sala e secando o chão com o rodo. A ênfase que pretendia dar a seu relato não era a da reclamação e nem a da crítica, mas sim a de que é possível dar boas aulas e desenvolver atividades interessantes em ambientes muito precários, desde que haja disposição e comprometimento da profissional.

Assim, além da falta de profissionais e de sua rotatividade, em função dos contratos de trabalho temporários, as condições estruturais e dos espaços físicos onde os trabalhos se desenvolvem também interferem em sua realização. Como referimos, crianças pequenas precisam ser levadas junto para atividades direcionadas aos adultos responsáveis, e inúmeros relatos ao longo de nossos encontros se referiram ao uso de espaços de trabalho que deveriam ser provisórios, mas se tornaram permanentes, que oferecem pouca segurança e são inadequados para os fins a que se destinam: varandas, 'puxados', toldos estendidos diante de trailers, visitas domiciliares em construções precárias embaixo de viadutos e de redes de alta tensão, contêineres que funcionam como salas de aula, encontros com grupos debaixo de árvores, casas alugadas com divisões internas que não atendem às neces- 
sidades do trabalho e dificultam a privacidade requerida em muitos desses atendimentos, além dos riscos - comuns colocados por redes elétricas e hidráulicas inadequadas.

A falta de computadores e de acesso à internet nas unidades de trabalho foi outro limitador reiterado em contextos investigados e também no trabalho de campo desta pesquisa.

Técnica da SMDS: Então os próprios CRAS não sabem o que é feito no outro. [...] A gente pensa que tem que comunicar vocês [...] mas nós não temos como comunicar vocês a não ser na nossa casa. Técnica da SMDS: Não tem nem internet? Técnica da SMDS: Não tem internet, agora nós ganhamos um computador, mas não tem nem impressora.

Técnica da SME: Faz uma semana que ganhamos e ainda não tá funcionando!

Técnica da SMDS: Então tudo é feito em casa. Técnica da SMDS: Só entre nós, com a iniciativa nossa, né? (Grupo Focal, 16/4/2010)

Num tempo em que os documentos normativos de todas as políticas prescrevem e supõem o registro e a disponibilização on-line de cadastros e outras informações, e o funcionamento das políticas é planejado em torno dessa suposição, a falta de computadores (e de manutenção básica quando há esses equipamentos) e de acesso à internet se transforma num problema muito importante: professoras que recebem estudantes vinculados ao PBF não são informadas disso, não têm acesso aos cadastros dessas famílias, ficam responsáveis apenas pelo atestado de frequência, sem intercomunicação com outras instituições também vinculadas ao seu atendimento. Informações e registros que interessam a mais de uma secretaria-e, dentro delas, a mais de um serviço - precisam ser geradas de novo, a cada vez que são demandadas, o que chega a ser um despropósito, considerando-se a insuficiência de técnicos/as para a realização das ações previstas.

Muita coisa se perde, nós temos um problema muito grande de documentação, [...] nós não temos computador aqui. Nós precisamos ir à secretaria [de Desenvolvimento Social] pra conseguir documentar as coisas, pra conseguir responder ofícios. [...] tudo tu tens que fazer uma cópia, mesmo que saia do teu bolso, já cansei de fazer isso, de tirar dinheiro do meu bolso pra tirar xerox, para digitar coisas na minha casa, no meu computador, porque não tinha tinta, nós chegávamos a ficar meses sem, como é que tu vais fazer um relatório assim sem isso? Às vezes faltam folhas, [...] coisas simples faltam [...] Se nós tivéssemos uma rede interligada de computadores, onde os dados das famílias estão lá, como estava

896 Estudos Feministas, Florianópolis, 22(3): 885-904, setembro-dezembro/2014 
${ }^{40}$ Analisamos tais dificuldades em MEYER et al. Quem aprende o que, com quem? Educação permanente, intersetorialidade e políticas de inclusa social, em avaliação para publicação.

${ }^{41}$ Graciela CARDARELLI e Mónica ROSENFELD, 2008.

${ }^{42} \mathrm{E}$ que temos analisado com o argumento da politização contemporânea da maternidade (MEYER, 2006) previsto no projeto da rede de proteção metropolitana, talvez ficasse mais tranquilo. (Entrevista - 10/1/2007)

Agregam-se a isso dificuldades mais complexas referentes à operacionalização de redes de atendimento integrado, compartilhamento de informações, possibilidades de encaminhamento e mesmo de conhecimento da multiplicidade de programas desenvolvidos nas próprias secretarias ou naquelas que compõem a rede de proteção social básica - saúde, educação, desenvolvimento social, justiça e segurança pública, entre outras -, a reduplicação de programas e de ações muito semelhantes, a falta de recursos em um e a devolução compulsória de recursos já liberados em outros, na medida em que não puderam ser gastos dentro dos prazos predeterminados, a distância entre o que se preconiza e os modos de viver a vida das populações-alvo, que confronta, muitas vezes, os/as técnicos/as com situações 'impensadas' em contextos 'impensáveis'. ${ }^{40}$

Dessa forma, pode-se dizer que condições básicas para o funcionamento das políticas sociais de Estado e de governo no Brasil atual estão muito longe de se materializar em qualquer das políticas e dos serviços que temos investigado. Ao mesmo tempo, pode-se afirmar que, em quase todos os casos, o que se espera é que essas condições se materializem por meio da ação isolada de indivíduos que devem assistir, educar e cuidar nesses contextos, o que incide, com diferentes ênfases e responsabilidades, tanto sobre a população usuária quanto os/as profissionais que a assistem. Graciela Cardarelli e Mónica Rosenfeld ${ }^{41}$ indicam, na mesma direção, que as instituições sociais, principalmente as que atuam com as populações pobres, assumem aspectos do universo simbólico que as rodeia, incorporando sentidos e, poderíamos dizer, representações de gênero que atravessam e dão forma a seus eixos de funcionamento.

Nessa perspectiva, é possível sustentar que a individualização da responsabilidade, tanto do sucesso quanto das falhas (sobretudo destas), não é prerrogativa da população que se assiste. ${ }^{42}$ Ela incide, com a mesma força, sobre aqueles que trabalham nessas políticas. Também nelas enunciados como vocacionalismo, afetividade e força de vontade, que são constitutivos de representações de um determinado tipo de feminino e de atividades profissionais vinculadas à educação, à saúde e à ação social, são fortemente mobilizados para impulsionar e/ou explicar ações bem e malsucedidas. Entretanto, importa sinalizar que, de forma muito mais ampla, esses enunciados se articulam e atuam na direção de validar modalidades educativas e de intervenção social que envolvem educação, saúde e assistência social, bem como para definir e posicionar a população-alvo, os territórios e as 
${ }^{43}$ ANZORENA, 2010.

${ }^{44}$ DUSCHATZKY, 2008.

${ }^{45}$ ANZORENA, 2010.

fronteiras da pobreza, os atores que devem atuar, os sujeitos técnicos/as, líderes, voluntários/as e mulheres-mães cuidadoras. Essa é uma das formas pelas quais o gênero, tomado como organizador do social e da cultura, opera nessas políticas. Claudia Anzorena ${ }^{43}$ e Silvia Duschatzky ${ }^{44}$ corroboram esse raciocínio sinalizando que, ao mesmo tempo que se promove a desresponsabilização do Estado no que se refere à assistência e à seguridade social, investe-se na otimização de 'competências femininas' que devem promover 'remendos' nas carências de serviços públicos e minorar efeitos destrutivos decorrentes da precariedade das relações de trabalho mais amplas. Assim, um dos efeitos da discursividade presente nas políticas de inclusão social é o de que a responsabilidade pelo trabalho de educação, assistência e cuidado de jovens, crianças e doentes, em contextos precários e mal remunerados, deve estar alicerçada, fundamentalmente, em competências historicamente representadas como femininas (ora preconizadas como responsabilidade de técnicos/as, ora das mulheres-mães); e nós acrescentamos que tudo isso independe do sexo dos indivíduos que as desenvolvem; ou seja, na perspectiva de gênero que adotamos, definir competências (assim como instituições, políticas, conhecimentos etc.) como sendo femininas não implica, necessariamente, que elas sejam desenvolvidas por mulheres, muito embora os textos programáticos raramente assumam essa noção.

Não podemos esquecer que, no tema do combate à pobreza e no incentivo às políticas de inclusão, órgãos internacionais como o Banco Mundial, a Organização das Nações Unidas para a Educação, a Ciência e a Cultura (Unesco) e o Fundo das Nações Unidas para a Infância (Unicef) valem-se dessas representações para confirmar e supervalorizar as tarefas relacionadas à produção de educação e(m) saúde como prioridades do Estado, reiterando, entretanto, que elas devem ser realizadas em casa, em unidades básicas de saúde (UBS) e/ou em centros comunitários, sob regência e responsabilidade sobretudo de mulheres-mães, enfermeiras, assistentes sociais, visitadoras, agentes de saúde e até mesmo voluntárias. E esses são outros desdobramentos do processo de feminização que estamos discutindo.

Na mesma direção de nosso argumento, Anzorena ${ }^{45}$ considera que políticas de inclusão social tendem a enfatizar a importância da incorporação do gênero, mas em muitos casos essa ênfase acaba funcionando para naturalizar lugares e funções socialmente construídas como femininas/ masculinas, desconsiderando os efeitos sociais e políticos que tais discursos promovem e reforçam. O funcionamento dessa engrenagem promove impactos tanto no que se refere à organização e à permanência de mulheres e homens em lugares específicos, como traz prejuízos a ambos no que se 
${ }^{46}$ ANZORENA, 2010, p. 742.

refere às condições de mercado e trabalho que continuam atravessadas por condições desiguais de gênero, produzidas "por determinantes materiais, culturais e ideológicos que estabelecem um tipo de trabalho mais adequado segundo $o$ gênero". ${ }^{46}$

Talvez situações e contextos como os aqui descritos demandem que tanto técnicas/os como diferentes categorias de agentes (comunitárias, visitadoras, promotoras sociais, voluntárias etc.) construam e mobilizem significados específicos para sua formação e para dar conta de funções nas quais necessitam lançar mão, cotidianamente, de 'qualidades altruístas' e de posicionamentos que os/as encaixem em representações de trabalhador/a 'afetuoso/a', 'comprometido/a' e 'criativo/a'. Fica subentendido aí um trabalho que vem marcado simbolicamente pela vulnerabilidade e pela necessidade de 'enfrentar' situações de extrema precariedade e violência, com o objetivo de 'fortalecer' e 'ajudar' a comunidade 'carente' devido à relevância social de ações - quase redentoras que precisam ser desenvolvidas com famílias ainda mais pobres e 'vulneráveis'.

\section{Para concluir}

Situações e relatos como estes dão pistas importantes de processos de legitimação de equipamentos públicos, em que a precariedade, a improvisação e a boa vontade parecem ser uma constante. Pode-se dizer que os/as próprios/as técnicos/as naturalizam e incorporam a escassez e a inoperância como dimensões inerentes ao seu trabalho (tal como a população pobre, alvo dos programas sociais) e assumem que precisam 'perseverar' e/ou 'tirar do próprio bolso' os recursos (ou incentivar e valer-se de trabalhos voluntários) para fazer cumprir as diretrizes de inclusão formuladas pelo Estado.

Nessa perspectiva é que vínhamos argumentando em nossos estudos que, quando se trata de populações pobres a serem interpeladas pelas políticas de inclusão social, acionamse sobretudo mulheres-mães, posicionando-as como responsáveis pelos problemas sociais enfrentados e como parceiras do Estado para promover sua solução. Neste artigo, ampliamos esse argumento, defendendo que, para realizar as propostas estabelecidas pelo Estado, profissionais são igualmente responsabilizados e precisam 'doar-se', 'fazer muito com pouco' e 'fortalecer redes de solidariedade', a fim de cumprir um conjunto de demandas que encobrem tensões políticas, sociais e econômicas muito mais amplas, profundas e complexas.

Isso nos leva a pensar sobre a complexidade da relação entre (e, em certos casos, incomensurabilidade entre) produção de conhecimento, justiça social, formação profissional e gestão 
pública, quando se tem como alvo a promoção de inclusão social, em contextos como o Brasil. Situar essa relação nesse processo que nomeamos feminização da inclusão social amplia essa complexidade não só porque se trata de políticas setoriais direcionadas fundamentalmente para determinados tipos de mulheres e suas famílias e executadas majoritariamente por profissionais mulheres, mas porque promover inclusão social, naquilo que envolve cuidar de si e dos outros, continua sendo representado como sendo 'da ordem do feminino'.

Assim, o exercício de cuidar de si e dos outros implica a feminização tanto de conhecimentos e práticas de promoção da inclusão quanto de instituições e sujeitos (profissionais e usuários) nelas implicados (e isso independe do sexo anatômico dos indivíduos envolvidos). Na medida em que assumimos que o gênero é um organizador do social e da cultura, tal feminização pode ser tomada como um efeito importante do processo de generificação das políiticas. Nessa direção, além de sinalizar para um processo social de generificação da inclusão que delimita importantes dificuldades técnicas e estruturais enfrentadas na implementação de políticas sociais, essas cenas e falas visibilizam fragilidades e limites que atingem não só as famílias usuárias como também aqueles que deveriam implementá-las, como, por exemplo, instabilidade no emprego, falta de condições materiais e estruturais para a realização do trabalho ou frustração por não dar conta das metas colocadas para o serviço. Argumentamos que isso contribui tanto para fortalecer a responsabilização do sujeito profissionalusuário/a pelo enfrentamento e pela solução dos problemas sociais como para conformar as próprias políticas públicas.

Importa, pois, vislumbrar linhas de fuga e problematizar essa trama, perguntando-nos, enquanto profissionais que atuamos nesses campos: que políticas, que conhecimentos e que intervenções se tornam necessárias nessa complexidade social? Como o conhecimento acumulado pelos estudos de gênero, articulado ao quadro conceitual da vulnerabilidade, pode contribuir para reconfigurar essa problemática e as questões que dela emergem?

\section{Referências}

ALVARENGA, Luiz Fernando. A arte de envelhecer ativamente: articulações entre corpo, gênero e sexualidade. 2012. Tese (Doutorado em Educação) - Programa de PósGraduação em Educação, Faculdade de Educação da UFRGS, Porto Alegre.

ANDRADE, Sandra. Juventudes e processos de escolarização: uma abordagem cultural. 2008. Tese (Doutorado em Educação) - Programa de Pós-Graduação em Educação, Faculdade de Educação da UFRGS, Porto Alegre. 
ANZORENA, Claudia. “'Mujeres': destinatarias privilegiadas de los planes sociales de inicios del siglo XXI - Reflexiones desde una perspectiva crítica de género". Estudos Feministas, v. 18, n. 2, p. 725-746, 2010.

ARANGO, Luz. "Género e Identidad en el Trabajo de Cuidado". DE LA GARZA, Enrique; NEFFA, Julio César (Orgs.). Trabajo, Identidad y Acción Colectiva. Cidade do México: Plaza y Valdés Editores, 2010. p. 81-108.

AYRES, José Ricardo de Carvalho Mesquita et al. "O conceito de vulnerabilidade e as práticas de saúde: novas perspectivas e desafios". In: CZERESNIA, Dina; FREITAS, Carlos Machado de (Orgs.). Promoção da saúde: conceitos, reflexões, tendências. Rio de Janeiro: Fiocruz, 2003. p. 117-140.

BAUMAN, Zygmunt. Modernidade e ambivalência. Rio de Janeiro: Jorge Zahar, 1999.

BRASIL, Ministério do Desenvolvimento Social. Serviço de Proteção e Atendimento Integral à Família (Paif). Disponível em: <http://www.mds.gov.br/assistenciasocial/ protecaobasica/servicos/protecao-e-atendimentointegral-a-familia-paif $>$. Acesso em: 20 jun. 2014.

BUARQUE, Cristovam. 100 perguntas e respostas que você precisa saber sobre a Bolsa-Escola. Brasília: 2000.

CARDARELLI, Graciela; ROSENFELD, Mónica. "Con las mejores intenciones: acerca de La relación entre El estado pedagógico y los agentes sociales". In: DUSCHATZKY, Silvia (Org.). Tutelados y asistidos: programas sociales, políticas públicas y subjetividad. Buenos Aires: Paidós, 2008. p.23-67.

CARVALHO, Marília Pinto de; VIANNA, Claudia Pereira. "Educadoras e mães de alunos: um (des) encontro". In: BRUSCHINI, Cristina; SORJ, Bila (Orgs.). Novos olhares: mulheres e relações de gênero no Brasil. São Paulo: Marco Zero/Fundação Carlos Chagas, 1994. p. 133-158.

CARVALHO, Marília Pinto de. "Trabalho docente e relações de gênero: algumas indagações". Revista Brasileira de Educação, n. 2, p. 77-84, 1996.

CARVALHO, Marília Pinto de. "Gênero e política educacional em tempos de incerteza". In: HYPOLITO, Álvaro Moreira; GANDIN, Luís Armando (Orgs.). Educação em tempos de incertezas. Belo Horizonte: Autêntica, 2000. p. 137-162.

CECCIM, Ricardo. "Educação permanente em saúde: desafio ambicioso e necessário". Interface: comunicação, saúde, educação, v. 9, n. 16, p. 161-168, 2005.

DAL'IGNA, Maria Cláudia. Família S/A: um estudo sobre a parceria família-escola. 2011. Tese (Doutorado em Educação) - Programa de Pós-Graduação em Educação, Faculdade de Educação da UFRGS, Porto Alegre.

DAMICO, José Geraldo Soares. Juventudes governadas: dispositivos de segurança e participação no Guajuviras 
(Canoas-RS) e em Grigny Centre (França). 2011. Tese (Doutorado em Educação) - Programa de Pós-Graduação em Educação, Faculdade de Educação da UFRGS, Porto Alegre.

DELOR, François; HUBERT, Michel. "Revisiting the concept of 'vulnerability'”. Social Science \& Medicine, v. 50, p. 15571570, 2000.

DOYAL, Lesley. "Sex, gender, and health: the need for a new approach". British Medical Journal, v. 323, n. 3, p. 10611063, 2001.

DUSCHATZKY, Silvia (Org.). Tutelados y asistidos: programas sociales, políticas públicas y subjetividad. Buenos Aires: Paidós, 2008.

FERNANDES, Letícia Prezzi. Nas trilhas da família... Como e o que meninos e meninas em situação de rua aprendem sobre relações familiares. 2008. Dissertação (Mestrado em Educação) - Programa de Pós-Graduação em Educação, Faculdade de Educação da UFRGS, Porto Alegre.

FOUCAULT, Michel. Segurança, território, população: curso no Collège de France (1977-1978). São Paulo: Martins Fontes, 2008.

GASTALDO, Denise et al. "Transnational health promotion: social well-being across borders and immigrant women's subjectivities". Wagadu, v. 2, p. 1-16, 2005.

GILES, Judy; MIDDLETON, Tim. Studying culture. A practical introduction. Oxford: Blackwell Publishers, 1999.

HALL, Stuart (Org.). Representation: cultural representation and signifying practices. London: Sage; Open University, 1997.

HIRATA, Helena; KERGOAT, Danièle. "Novas configurações da divisão sexual do trabalho". Cadernos de Pesquisa, v. 37, n. 132, p. 595-609, dez. 2007.

HIRATA, Helena. "Tendências recentes da precarização social e do trabalho: Brasil, França, Japão". Caderno CRH, v. 24, n. especial, p. 15-22, 2011.

HYPOLITO, Álvaro Moreira. Processo de trabalho docente: uma análise a partir das relações de classe e de gênero. 1994. Dissertação (Mestrado em Educação) - Faculdade de Educação da UFMG, Belo Horizonte.

KERGOAT, Danièle. "Da divisão do trabalho entre os sexos". Tempo Social, n. 1, v. 2, p. 88-96, 1989.

KLEIN, Carin. "...um cartão [que] mudou a nossa vida"? Maternidades veiculadas e instituídas no Programa Nacional Bolsa Escola. 2003. Dissertação (Mestrado em Educação) - Programa de Pós-Graduação em Educação, Faculdade de Educação da UFGRS, Porto Alegre.

KLEIN, Carin. "Educação de mulheres-mães pobres para uma 'infância melhor'”. Revista Brasileira de Educação [online], v. 17, n. 51, p. 647-660, 2012. 
KLEIN, Carin. Biopolíticas de inclusão social e produção de maternidades e paternidades para uma "Infância Melhor". 2010. Tese (Doutorado em Educação) - Programa de Pós-Graduação em Educação, Faculdade de Educação da UFGRS, Porto Alegre.

KLEIN, Carin; MEYER, Dagmar; BORGES, Zulmira. "Políticas de inclusão social no Brasil contemporâneo e educação da maternidade". Cadernos de Pesquisa, v. 43, n. 150, p. 906-923, dez. 2013.

LAVINAS, Lena; SORJ, Bila. "O trabalho a domicílio em questão: perspectivas brasileiras". In: ROCHA, Maria Isabel Baltar (Org.). Trabalho e gênero: mudanças, permanências e desafios. São Paulo: Ed. 34, 2000. p. $211-236$.

LOPES, Eliane Marta Teixeira. "A educação da mulher: a feminização do magistério". Teoria \& Educação, n. 4, p. 22-40, 1991.

LOURO, Guacira Lopes. "Gênero e magistério: identidade, história, representação". In: CATANI, Denice et al. Docência memória e gênero: estudos sobre formação. São Paulo: Escrituras Editora, 1997. p. 75-84.

MARIANO, Silvana. "Cidadania na perspectiva das mulheres pobres e papéis de gênero no acesso a políticas assistenciais". Revista Brasileira de Ciência Política, n. 2, p. 119-157, jul./dez. 2009.

MARIANO, Silvana; CARLOTO, Cássia. "Gênero e combate à pobreza: programa bolsa família". Revista Estudos Feministas, v. 17, n. 3, p. 901-908, dez. 2009.

MEYER, Dagmar. "A politização contemporânea da maternidade: construindo um argumento". Gênero: Núcleo Transdisciplinar de Estudos de Gênero, v. 6, n. 1, p. 81-104, 2006. Vulnerabilidade, programas de inclusão social e práticas educativas: uma abordagem na perspectiva dos estudos de gênero e culturais. 2008a. Projeto de pesquisa - Porto Alegre: Faculdade de Educação da UFRGS.

"Gênero e educação: teoria e política". In: LOURO, Guacira Lopes; NECKEL, Jane Felipe; GOELLNER, Silvana (Orgs.). Corpo, gênero e sexualidade: um debate contemporâneo na educação. Petrópolis: Vozes, 2011 . v. 1, p. 9-27.

MEYER, Dagmar et al. A educação "da família" como estratégia governamental de inclusão social: um estudo situado na interface dos estudos culturais, de gênero e de vulnerabilidade. 2008b. Relatório de Pesquisa - Porto Alegre: Faculdade de Educação da UFRGS.

MEYER, Dagmar; KLEIN, Carin; FERNANDES, Letícia. "Noções de família em políticas de 'inclusão social' no Brasil contemporâneo". Estudos Feministas, v. 20, n. 2, maio/ ago. 2012. 
RAICHELIS, Raquel. "Intervenção profissional do assistente social e as condições de trabalho no Suas". Serviço Social \& Sociedade, n. 104, p. 750-772, out./dez. 2010.

RIO GRANDE DO SUL (Estado). Secretaria da Saúde do Estado do Rio Grande do Sul. Programa Primeira Infância Melhor. Guia de orientação para GTM, monitor e visitador. Contribuições para políticas na área do desenvolvimento infantil. Porto Alegre: Relâmpago, 2007.

SHORE, Cris; WRIGHT, Susan. Antropology of policy: critical perspectives on governance and power. London: Routledge, 1997.

SILVA, Tomaz Tadeu da. O currículo como fetiche: a poética e a política do texto curricular. Belo Horizonte: Autêntica, 1999.

[Recebido em fevereiro de 2013, reapresentado em julho de 2014 e aceito para publicação em julho de 2014]

Vulnerability, Gender and Social Policies: the Feminization of Social Inclusion Abstract: The article unfolds from a survey conducted with managers and technicians related to municipal secretariats involved with the implementation of policies and programs of social inclusion, in a city of the Metropolitan area of Porto Alegre/RS. From the perspective of gender studies and post-structuralist cultural studies, we discuss a movement of genderification that we have named "feminization of social inclusion", focusing on the employment situation and working conditions, the infrastructure of services and the ways in which professionals/technicians perceive themselves on the implementation of policies. We argue that promoting social inclusion presupposes to develop and play a set of capabilities represented as being from 'the order of the feminine', that are constitutive of the feminization incorporated and made by policies. Key Words: Vulnerability; Gender; Policies; Social Inclusion. 